\title{
Sentencia 149/08, de trece de marzo, Audiencia Provincial de Barcelona, Sección decimosexta.
}

AUTORA: Judith Solé Resina. Profesora Titular de Derecho Civil de la Universidad Autónoma de Barcelona

TÍTULO: Sentencia 13.03.2008, Audiencia Provincial de Barcelona

FECHA DE PUBLICACIÓN: marzo 2010

LUGAR DE PUBLICACIÓN: dA web Center, marzo 2010

Link interno: $\underline{\text { Sentencia }}$

Audiencia Provincial de Barcelona

Actuaciones:

Magistrado ponente: D. Jordi Seguí Puntas

Fecha: 13.03.2009

Comentario sobre la Sentencia 149/08, de trece de marzo, de la Audiencia Provincial de Barcelona. Sección decimosexta.

Los HECHOS sobre los que versa este supuesto son los siguientes:

Don Héctor presentó demanda de juicio ordinario contra Doña María Luisa ante el Juzgado de $1^{\mathrm{a}}$ Instancia $\mathrm{n}^{\mathrm{o}} 10$ de los de Barcelona en la que alegaba: $1^{\mathrm{o}}$ que el actor que era propietario de un gato persa de pelo largo llamado Sam; $2^{\circ}$ que se lo regaló su padre cuando tenía 13 años y era un gato sano y feliz; $3^{\circ}$ que en junio de 2000 se le diagnostica al gato un megacolon, que le producía problemas de estreñimiento; $4^{\circ}$ que en julio de ese año fue sometido a cirugía, practicándole una colectomía en la Clínica Tot Cat; $5^{\circ}$ que la operación fue un éxito y Sam comenzó a hacer una vida normal, si bien tuvo algún episodio de estreñimiento que fue solucionado en Tot Cat mediante la aplicación de agua jabonosa; $6^{\circ}$ que el día 26 de marzo de 2002 tuvo un nuevo estreñimiento y el actor y su padre habiendo visto que el método de curación era sencillo, decidieron llevar a Sam a la veterinaria "de cabecera" que se ocupaba de los reconocimientos periódicos y vacunación, que es la parte demandada; $7^{\circ}$ que la doctora examinó a Sam y les envió a comprar un enema Casen de $250 \mathrm{cc}$ informándoles la farmacéutica que para un gato con 80 cc sería suficiente; $8^{\circ}$ que la doctora se lo puso entero y de golpe, empezando Sam a vomitar y sacar líquido por la boca y el recto, maullando de dolor; $9^{\circ}$ que la doctora les indicó que había que comprar dos enemas más de $250 \mathrm{cc}$, lo que extrañó nuevamente a la farmacéutica; $10^{\circ}$ que la demandada volvió a introducirle otros $250 \mathrm{CC}$ al gato, siendo el total introducido el equivalente a 10 litros para una persona adulta; $11^{\circ}$ que el gato vomitó muchísimo y se quedó desmayado, con los ojos en blanco sin que la doctora se inmutase; $12^{\circ}$ que Sam empezó a convulsionar y la doctora pretendía ponerle el tercer enema, optando el demandante y su padre, viendo el sufrimiento del gado, por marcharse a la clínica Tot Cat; $13^{\circ}$ que Sam quedó ingresado en la clínica, no cesando las convulsiones, perdiendo totalmente la conciencia, hasta que, por la noche, viendo que su estado empeoraba por minutos, se recomendó la eutanasia como única opción para evitarle más sufrimientos; $14^{\circ}$ que la actuación de la doctora fue incomprensible, siendo evidente su mala praxis; $15^{\circ}$ que dicha mala praxis se puso en conocimiento del Colegio de Veterinarios, siendo sancionada por una falta deontológica; $16^{\circ}$ que junto al daño material del valor del gato, 
unos 900 euros, se produjo un daño mayor y ello por cuanto el demandante, que padece una disminución psíquica, ha empeorado en su estado como consecuencia del episodio relatado en un $28 \%$. La cantidad total finalmente reclamada como indemnización es de $4.400 €$.

La demandada se opone a la demanda, interesando sentencia desestimatoria y alegando: $1^{\circ}$ prescripción de la acción de responsabilidad extracontractual; $2^{\circ}$ inexistencia de mala praxis por cuanto no hay relación causal entre el fallecimiento de Sam y el tratamiento realizado por la demandada; $3^{\circ}$ pluspetición respecto la indemnización, discrepando en el valor del gato, del que se afirma que no era un gato persa sino un cruce de razas que carece de valor el mercado; $4^{\circ}$ pluspetición también por la falta de relación entre la defunción del gato y la disminución psíquica del demandante.

El Juzgado de $1^{\text {a }}$ Instancia $\mathrm{n}^{\mathrm{o}} 10$ de los de Barcelona, en Sentencia de 25 de enero de 2007 (Sentencia) estima parcialmente la demanda y condena a la demandada a satisfacer al actor la suma de $2.400 €$, de los cuales $900 €$ por daños patrimoniales (valor del animal sacrificado) y $1.500 €$ por daños morales.

Contra dicha resolución, la parte demandada interpone recurso de apelación ante la Audiencia Provincial. La Sentencia de la Audiencia estima en parte el recurso y reduce el valor de la indemnización a $1.950 €$, al entender que el valor del gato no podía ascender a $900 €$, tal como había valorado la Sentencia de Instancia, por no ser un gato de raza, y fijar dicho valor en $450 €$, confirmando en lo demás a sentencia recurrida.

Los temas más destacados que se plantean en este caso concreto son los siguientes:

- La cuestión de si la relación entre el veterinario y el propietario del animal debe calificarse como una relación contractual o extracontractual. El principal efecto, por lo que aquí interesa, se centra, en que el plazo de prescripción de la acción es distinto en uno u otro caso;

- La configuración de la responsabilidad por mala praxis del veterinario. Su relación con el incumplimiento de la obligación y la carga de la prueba, cuestión que se halla directamente relacionada con la clasificación de la obligación del veterinario, como una obligación de medios o una obligación de resultado; y

- La determinación de los conceptos indemnizables y su cuantificación.

\section{1.- La relación entre el veterinario y el dueño del animal es una relación contractual.}

En la primera instancia, se plantea la cuestión de la prescripción de la acción ejercitada por la demandante. En este punto es esencial determinar si con ella se reclama un supuesto de responsabilidad contractual o de responsabilidad extracontractual pues, como es sabido, la acción de responsabilidad contractual cuenta con un plazo de prescripción de la acción de tres años en los supuestos contemplados en el art. 1967 CC o de quince años, cuando no tienen señalado un término especial de prescripción (art. 1964 CC); mientras que, el plazo de prescripción de la acción de responsabilidad extracontractual, es un año (art. 1968 CC). Todo ello, según el Código Civil Español, que es la norma que resulta de aplicación al caso concreto, de acuerdo con la Disposición Transitoria Única Ley 29/2002, de 30 de diciembre, Primera Ley del Código Civil de Cataluña, que establece el criterio general de la irretroactividad de esta 
norma si el plazo de prescripción establecido por la ley anterior era más corto que el que establece la nueva ley, como es el caso del plazo de prescripción de la responsabilidad extracontractual, que en Cataluña pasa de uno a tres años. Aunque hay que señalar que actualmente, ya no se plantearía esta cuestión, pues la norma aplicable sería el Código Civil de Cataluña donde los plazos de prescripción de la acción de responsabilidad contractual y de la acción de responsabilidad extracontractual coinciden en los tres años (art. 121-21 CCCat).

Es evidente que entre demandante y demandada existió una relación contractual, pues hubo un acuerdo de voluntades por el cual una de las partes se comprometía a prestar un servicio a cambio de un precio. Concretamente, se celebró un contrato de servicios con forma verbal (art. $1544 \mathrm{CC}$ ). Siendo así, para que exista responsabilidad contractual habrá que demostrar que hubo un incumplimiento de la obligación principal del prestador del servicio que ocasionó un daño a la contraparte que hay que indemnizar (art. $1101 \mathrm{CC}$ ). En el supuesto que se descarte la existencia de responsabilidad contractual, todavía podría plantearse (si la acción no hubiera prescrito) la posibilidad de que existiera responsabilidad extracontractual derivada de una acción u omisión que causa daño a otro, interviniendo culpa o negligencia (art. 1902 CC).

El Juzgado de $1^{\text {a }}$ Instancia califica acertadamente la relación entre las partes como un contrato de arrendamiento de servicios veterinarios, aunque utiliza una nomenclatura un tanto anacrónica para referirse a esta institución contractual, y examina a continuación si se dan los requisitos necesarios para apreciar la existencia de responsabilidad contractual, que dice son: a) la existencia de una previa obligación; b) su incumplimiento debido a culpa, negligencia o falta de diligencia del demandado y no a caso fortuito o fuerza mayor; c) la realidad del daño; y d) el nexo causal eficiente entre aquella conducta y el daño producido.

2.- La obligación del veterinario es, en principio, una obligación de medios. La carga de la prueba corresponde a quien alega el incumplimiento, aunque se admite cierta flexibilización.

El Juzgado de $1^{\text {a }}$ Instancia parte de la asimilación del contrato celebrado con veterinarios con el contrato celebrado con médicos y considera, de este modo, aplicable la jurisprudencia que califica la obligación de los médicos como una obligación de medios y no de resultado; esto es, como una obligación, no de obtener la recuperación o sanidad del enfermo; sino de proporcionarle todos los cuidados que requiera y procurar su curación, de acuerdo con el estado de la ciencia. Siendo así, el veterinario cumple si actúa con la diligencia debida, que es la propia de un buen profesional, aunque no consiga el resultado de la curación del animal; mientras que sólo habrá incumplimiento, sea cual sea el resultado del tratamiento o intervención, en caso de actuación negligente.

También descarta dicho Juzgado -citando las STSS de 7 de febrero de 1990, 13 de octubre de 1992, 23 de marzo de 1993, 20 de marzo de 2001, 23 de marzo de 2001 y 6 de febrero de 2001- que "toda clase de responsabilidad más o menos objetiva, sin que opere la inversión de la carga de la prueba, admitida para los daños de otro origen, estando, por tanto, a cargo del paciente (o de sus familiares, en caso de fallecimiento de éste) la prueba de la culpa o negligencia correspondiente, en el sentido de que ha de dejar acreditado en el proceso que el acto médico o quirúrgico enjuiciado fue realizado 
con infracción o no sujeción a las técnicas médicas o científicas exigibles para el mismo (lex artis ad hoc)". Aunque admite la flexibilización de la prueba, de acuerdo con lo que dispone el TS en la Sentencia de 2 de diciembre de 1996 en la que afirma que "debe establecerse que, no obstante sea la profesión médica una actividad que exige diligencia en cuanto a los medios que se emplean para la curación o sanación, adecuados según la "lex artis ad hoc" no se excluye la presunción desfavorable que pueda generar un mal resultado, cuando éste por su desproporción con lo que es usual comparativamente, según las reglas de la experiencia y el sentido común, revele inductivamente la penuria negligente de los medios empleados, según el estado de la ciencia y las circunstancias de tiempo y ligar, o el descuido en su conveniente y temporánea utilización”.

En nuestra opinión es evidente que los supuestos de prestación de servicios médicos y de prestación de servicios de veterinarios presentan identidad de razón, a los efectos de calificar la obligación principal del prestador de servicios. Y entonces, es cierto que en la mayoría de las ocasiones se configura como una obligación de medios o actividad. Aunque no puede descartarse que dicha obligación pueda configurarse en algunos casos como una obligación de resultado -del mismo modo que también puede el médico comprometerse con una obligación de resultado- lo que sucede cuando así lo convienen las partes, por ejemplo, cuando el veterinario se compromete expresamente a curar una determinada patología o corregir una discapacidad, o cuando se deriva del propio contenido de la obligación, como cuando el veterinario se obliga a esterilizar a un animal.

Entonces, por norma general se podrá calificar, como acertadamente hace la Sentencia de Instancia, la obligación del veterinario como una obligación de medios o de actividad. Y habrá incumplimiento, insistimos, no cuando no se consiga el resultado perseguido (la sanación del animal), sino cuando no se actúe en el tratamiento con la diligencia propia de un buen profesional o de acuerdo con el estado actual de la ciencia. La carga de la prueba del incumplimiento de la obligación de medios pesa sobre la parte que lo alega, que debe demostrar que existe culpa o negligencia en la actuación del profesional, aunque es cierto que los tribunales admiten una cierta flexibilización de la prueba cuando el resultado del servicio es absolutamente desproporcionado o es en si mismo una evidencia de la negligencia en la actuación.

El Juzgado de $1^{\text {a }}$ Instancia $\mathrm{n}^{\mathrm{o}} 10$ de Barcelona considera probada la existencia de nexo causal entre el tratamiento administrado por la veterinaria y el fallecimiento del gato Sam: entiende que queda acreditado que el enema suministrado tanto por su composición como por su cantidad, estaba especialmente contraindicado para la patología previa sufrida por Sam, algo que la demandada debía conocer, por lo que vulneró la buena praxis veterinaria, incumpliendo de este modo su obligación de servicios y ocasionando un daño que debe repararse.

La Audiencia Provincial confirmó la apreciación de negligencia profesional de la veterinaria demandada.

\section{3.- La indemnización incluye el daño material y el daño moral}

La reclamación quedó definitivamente fijada en $900 €$ en concepto de daño patrimonial, y en $3.500 €$ en concepto de daño moral. 
En cuanto al daño material debe valorarse el valor comercial del gato. Tratándose de un gato de raza persa, su precio de mercado oscila entre los 900 y los $1200 €$. Por este motivo el Juzgado de $1^{\text {a }}$ Instancia condena a pagar $900 €$ en este concepto a la demandada. Será en apelación cuando la Sentencia de la Audiencia Provincial de Barcelona rebaje esta cantidad a $450 €$ por considerar que queda acreditado que el gato Sam no era de pura raza sino un cruce de razas siamés y persa, y que al no constar criterio alternativo para la valoración de esta especie se le asigna dicho valor. Sin embargo, no se plantean cuestiones de especial interés con relación a la indemnización del daño patrimonial, que ha de quedar fijada en función del valor del animal en el mercado.

Más compleja resulta la reparación del daño moral, que ha de concretarse en una indemnización con la finalidad de proporcionar en la medida de lo humanamente posible una satisfacción como compensación al sufrimiento causado (STSS 7 de diciembre de 2006, 4 de octubre de 2006, entre otras).

Es sabido que la jurisprudencia tiene reconocido que existe un daño moral indemnizable cuando se produce un sufrimiento o padecimiento psíquico que puede presentarse de muy diversas formas y provocar en quien lo padece situaciones de impotencia, zozobra, ansiedad, angustia, inquietud, pesadumbre, temor o presagio de incertidumbre, trastorno de ansiedad, impacto emocional, etc. (STS, de 22 de mayo de 1995, de 19 de mayo de 1996, de 27 de septiembre de 1999, 22 de mayo de 2000, entre otras). Aunque también se reconoce la inexistencia de parámetros que permitan traducir en términos económicos el sufrimiento en que consiste (STS 10 de febrero de 2006) y la falta de fórmulas generalistas, absolutamente inadecuadas para esta situación, por lo que la determinación de la cuantía en que en cada caso debe fijarse la indemnización por el daño moral debe quedar necesariamente en manos de los tribunales que habrán de resolver de forma casuística, según su prudente arbitrio (STS de 9 de mayo de 1984 y 5 de octubre de 1998, entre otras).

Es en esta competencia que el Juzgado de $1^{\text {a }}$ Instancia cuantifica el daño moral que sufre el dueño del animal, considerando que tenía el gato desde los 13 años y que las circunstancias en las que se produjo su muerte, totalmente sorpresiva y especialmente dolorosa para el animal, en $1.500 €$.

La Audiencia Provincial por su parte, confirma en este extremo la Sentencia apelada, máxime, afirma, cuando la minusvalía que sufre el demandante (trastornos graves de la personalidad de etiología idiopática) y la traumática ruptura del lazo afectivo con el animal hubo de provocarle un grave sufrimiento.

\section{dA derecho ANIMAL}

la web center de los animales con derecho

derechoanimal.info

Julio- 2010 